\title{
Corrigendum: Positive and Negative Symptoms in Schizophrenia Relate to Distinct Oscillatory Signatures of Sensory Gating
}

\author{
Julian Keil *, Yadira Roa Romero, Johanna Balz, Melissa S. Henjes and Daniel Senkowski \\ Multisensory Integration Group, Department of Psychiatry and Psychotherapy, Charité - Universitätsmedizin Berlin, St. \\ Hedwig Hospital, Berlin, Germany
}

Keywords: inter-trial coherence, power, gamma-band, alpha-band, phenotype, cluster analysis

\section{A corrigendum on}

Positive and Negative Symptoms in Schizophrenia Relate to Distinct Oscillatory Signatures of Sensory Gating

\section{OPEN ACCESS}

Edited and reviewed by: Edmund C. Lalor,

Trinity College Dublin, Ireland

*Correspondence:

Julian Keil

julian.keil@charite.de

Received: 29 March 2016 Accepted: 01 April 2016 Published: 14 April 2016

Citation:

Keil J, Roa Romero Y, Balz J, Henjes MS and Senkowski D (2016) Corrigendum: Positive and Negative Symptoms in Schizophrenia Relate to

Distinct Oscillatory Signatures of Sensory Gating.

Front. Hum. Neurosci. 10:162. doi: 10.3389/fnhum.2016.00162 by Keil, J., Roa Romero, Y., Balz, J., Henjes, M., and Senkowski, D. (2016). Front. Hum. Neurosci. 10:104. doi: 10.3389/fnhum.2016.00104

Throughout the manuscript and in the references, we have ascribed the article "Sensory disturbances, inhibitory deficits, and the P50 wave in schizophrenia" by Premysl Vlcek and colleagues erroneously to the second author, Petr Bob. Thus, references to "Bob et al., 2014" should read "Vlcek et al., 2014" and the respective reference should read:

Vlcek, P., Bob, P., and Raboch, J. (2014). Sensory disturbances, inhibitory deficits, and the P50 wave in schizophrenia. Neuropsychiatr. Dis. Treat. 10, 1309-1315. doi: 10.2147/NDT.S64219

\section{AUTHOR CONTRIBUTIONS}

All authors listed, have made substantial, direct and intellectual contribution to the work, and approved it for publication.

Conflict of Interest Statement: The authors declare that the research was conducted in the absence of any commercial or financial relationships that could be construed as a potential conflict of interest.

Copyright (C) 2016 Keil, Roa Romero, Balz, Henjes and Senkowski. This is an open-access article distributed under the terms of the Creative Commons Attribution License (CC BY). The use, distribution or reproduction in other forums is permitted, provided the original author(s) or licensor are credited and that the original publication in this journal is cited, in accordance with accepted academic practice. No use, distribution or reproduction is permitted which does not comply with these terms. 